\title{
After the Horse has Bolted: A Reply to Garner et al. (2009)
}

\author{
Kerry M. Kriger and Jean-Marc Hero \\ Centre for Innovative Conservation Strategies, School of Environment, Griffith University, Gold Coast, QLD 9222, Australia
}

The intercontinental trade and transport of amphibians has been linked directly to disease spread and the subsequent extinction of amphibian species worldwide. Garner et al. (2009) invoke historical precedents and current trade practices to conclude that "imposing trade restrictions will require substantial time and effort with no guarantee of success...". They use this rationale to downplay the importance or effectiveness of banning or reducing the amphibian trade, instead espousing their belief that diseaserelated amphibian declines can be controlled through a combination of post-hoc actions, such as improved stakeholder education, disease testing, and continued research into techniques for mitigating the effects of disease in affected areas. Although these actions are an important component of a comprehensive strategy to manage a widely distributed disease, we maintain that a virtually complete ban on all unnecessary long-distance trade and transport of live amphibians is required to prevent the spread of novel pathogens and the extinctions that they will inevitably cause. This is because: (1) it takes only one infected individual to initiate an epizootic; (2) there exists neither the machinery nor the manpower to perform disease diagnostics on millions of amphibians per year; (3) even with routine testing and quarantines, diseased individuals would inevitably pass undetected; (4) it is not possible to test for diseases that have yet to be discovered; (5) history dem- onstrates that waterborne pathogens (such as Batrachochytrium dendrobatidis) can become globally ubiquitous long before we even know of their existence (Kriger and Hero 2009); and (6) we are currently unable to eradicate from the wild, let alone control, even those diseases for which we have the most in-depth understanding. We could therefore say "eradicating disease from the wild will require substantial time and effort with no guarantee of success".

An ounce of prevention is worth a pound of cure. We agree that substantial time and effort with no guarantee of success is inevitable, but a mass extinction of amphibians is occurring, and drastic actions are warranted. Our efforts should optimally be directed toward preventing the causes of the problems, rather than healing symptoms after global extinctions have already occurred (closing the gate after the horse has bolted).

\section{REFERENCES}

Garner TWJ, Stephen I, Wombwell E, Fisher MC (2009) The amphibian trade: bans or best practice? EcoHealth 6(1). doi: 10.1007/s10393-009-0233-1

Kriger KM, Hero J-M (2009) Chytridiomycosis, amphibian extinctions, and lessons for the prevention of future panzootics. EcoHealth 6(1). doi:10.1007/s10393-009-0228-y 